\title{
DETERMINATION OF EFFECTIVE MECHANICAL PROPERTIES OF PARTICLE - REINFORCED COMPOSITE MATERIAL WITH USE OF NUMERICAL APPROACH
}

\author{
Grzegorz Mieczkowski \\ Bialystok University of Technology, Poland \\ g.mieczkowski@pb.edu.pl
}

\begin{abstract}
The work presented is related to determination of effective mechanical properties of a PRMMCs (particle reinforced metal matrix composites) composite. Such composites, because of their specific wear resistance (high-temperature work capability) and high strength properties compared to mass, are often used in many devices in industry and agriculture. The mechanical properties of the PRMMCs can be determined based on experimental research. However, since the volume fraction of the reinforcement and its geometry significantly affect the resulting mechanical properties of the composite, determining them through experimental research would require a lot of work and would involve high costs. So, there is a legitimate need to develop alternative methods. In the literature, one can find analytical models enabling the determination of limit values of such parameters as elastic moduli or Poisson's ratio. The authors usually assume a uniform distribution of reinforcement particles and do not take into account the effect of their size on the effective mechanical properties. An alternative method of homogenizing the properties of heterogeneous materials may be an approach based on the use of numerical methods. Therefore, the article presents a methodology for determining the effective mechanical properties of PRMMCs using the finite element method (FEM). The developed method enables determination of Young's modulus, Poisson's ratio and density of composite, taking into account the impact of the random distribution of reinforcement particles, as well as their size and volume fraction. To verify the proposed approach, effective mechanical properties have been determined for a frequently used material particle - reinforced aluminium matrix composite (PRAMCs). The results obtained were compared with the literature data. The investigations show satisfactory compliance of the obtained results with both experimental data and analytical solution.
\end{abstract}

Keywords: homogenization, effective properties, composite materials.

\section{Introduction}

Composite materials, because of their utility features (wear resistance, high-temperature ability) and high strength properties compared to mass, are nowadays often used in the automotive [1-2], aerospace [3-4] and agricultural industry [5-6]. These are anisotropic materials with a more or less periodic structure [7-12].

Particle-reinforced metal matrix composites (PRMMCs) are among the often used structure materials. Their strength and stiffness properties depend to a large extent on the microstructure and properties of the matrix and reinforcement.

Many authors dealt with the study of the effective mechanical properties of such composites. In papers [13-16], analytical formulas are given to determine the limit values of parameters, such as elastic and buckling moduli or the Poisson's ratio, taking into account the volume fraction of reinforcement. In the solutions obtained, the authors assumed regular distribution of reinforcement particles and did not take into account the influence of their size on effective mechanical properties.

In recent years, along with the development of numerical methods, the approaches based on FEM (finite element method) are used (together with experimental research) for strength tests and modelling of many physical phenomena, such as piezoelectricity, flow and friction phenomena [17-29].

FEM can also be used to determine the effective properties of composite materials. An important advantage of using this method for investigating properties of composites is the fact that numerical studies are less expensive and time-consuming than experimental ones. Most commercial FEA software enables modelling of composite materials with reinforcements of any shape, size and spatial distribution. Curious studies on the estimation of effective elastic properties and durability of particlereinforced composites using FEM can be found, for example, in [30-33].

Many authors, for example [30-33], model particle - reinforced metal matrix composites as a 2D plane problem. Such simplification may cause errors in the results obtained. Therefore, the presented work presents a methodology for determining the effective mechanical properties of PRMMCs using three-dimensional models. The developed method enables determination of Young's modulus, 
Poisson's ratio and density of composites, taking into account the impact of random distribution of reinforcement particles, as well as their size and volume fraction.

\section{Materials and methods}

The FEM approach was used to determine the effective Young's moduli and Poisson's ratios. The selected 3D model of the composite microstructure is shown in Figure 1.
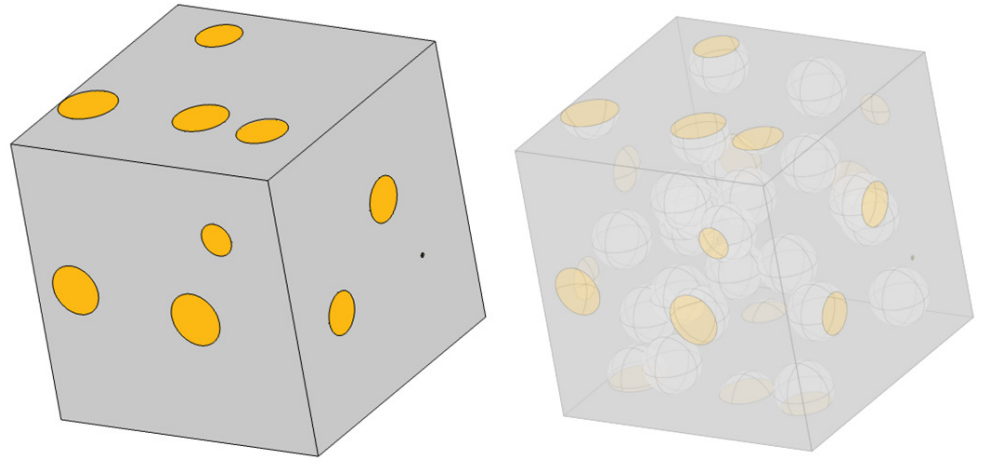

Fig. 1. Composite microstructure of particle diameter $0.05 \mathrm{~mm}$ and volume fraction $10 \%$

The matrix material is a cube with $a=1 \mathrm{~mm}$ on a side (grey colour in Figure 1) while the reinforcement particles have a spherical shape. In the prepared models, the location of the spheres is determined randomly in all directions. To determine the random location of individual spheres representing the reinforcement material, a pseudo-random number generator (PRNG) built-in the Java environment was used. First, the real number Ro is drawn: $0<$ Ro $\leq 1$. A uniform distribution of probabilities is assumed when drawing the number Ro. The product of Ro and $a$ is treated as the $x_{i}, y_{i}$ or $z_{i}$ coordinate specifying the centre of the ith reinforcement particle.

What is more, the spheres could not penetrate each other. To give the composite microstructure nature as periodic as possible, when the sphere is partially positioned behind the matrix material, part of the sphere protruding is transferred to the opposite wall of the cube. To obtain the assumed distribution of reinforcement particles, it was necessary to develop a new program code, written in Java language (algorithm of the program is given in Figure 2).

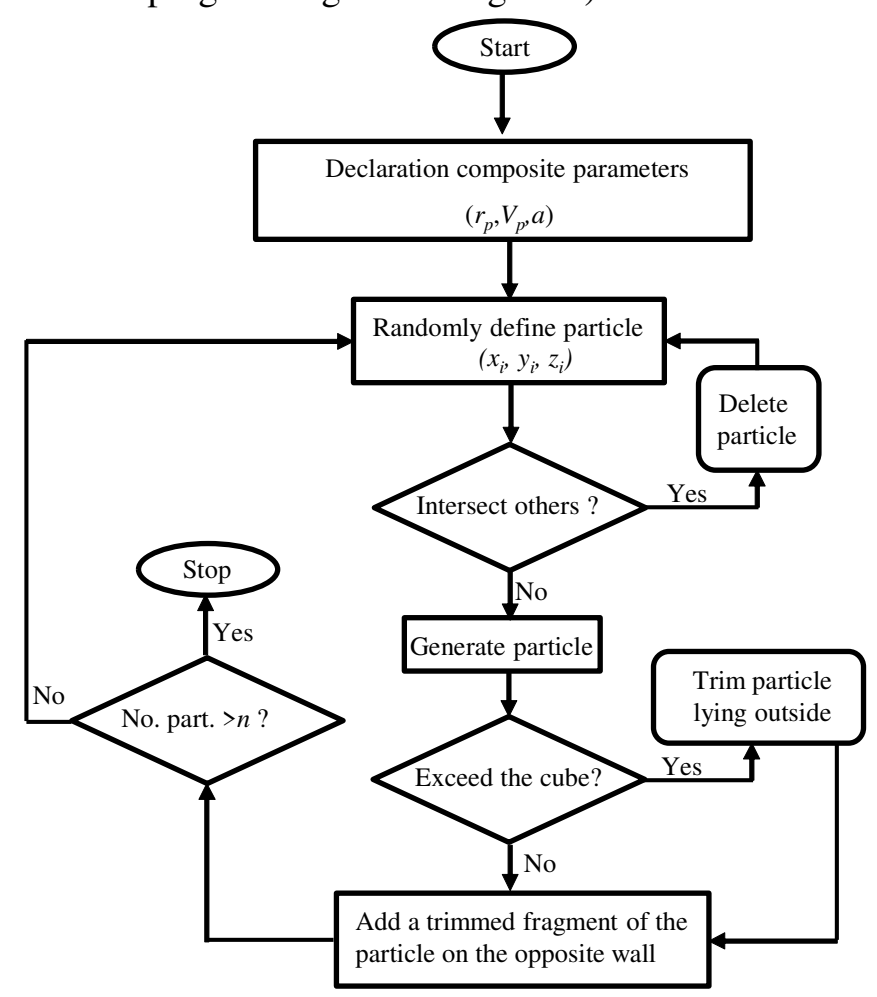

Fig. 2. Algorithm of the program for generating 3D models of composite microstructures 
The program can generate automatically 3D models of composite microstructures with freely defined particle size ( $r_{p}$ - the radius of a sphere) and reinforcement volume fraction $V_{p}$.

One goal of the work was to determine the effect of the particle size and their volume fraction on the fracture process. Therefore, 3Dmodels with different particle sizes $r_{p}$ and the volume fraction of reinforcement $V_{p}$ were prepared.

The relationship between the side of the cube $a[\mathrm{~mm}]$, the volume fraction of the reinforcement $V_{p}$ $(\%)$, the sphere radius $r_{p}(\mathrm{~mm})$ and the number of particles is given by the formula (1):

$$
n=\frac{3 a^{3} V_{p}}{400 \pi r_{p}^{3}}
$$

Both the radius of the particle and the volume fraction of the reinforcement were selected in such a way that they correspond to the real limits of the chosen composites PRMMCs. From the group of composites PRMMCs, particle - reinforced aluminium matrix composites (PRAMCs) with SiC reinforcement were selected for analysis.

The 3D models were then used in numerical calculations of FEM (made using the Comsol Multiphysics software). The models of the composite are described using quadratic tetrahedral finite elements, with increased densities at the interface surfaces of the matrix and reinforcement. The finite element mesh and applied boundary conditions are shown in Figure 3. On the surfaces $a, b, c$, symmetry boundary conditions were assumed. As regards the load boundary conditions, to the surface opposite to the surface "a" a constant displacement $u_{x}=0.001 \mathrm{~mm}$ was applied.

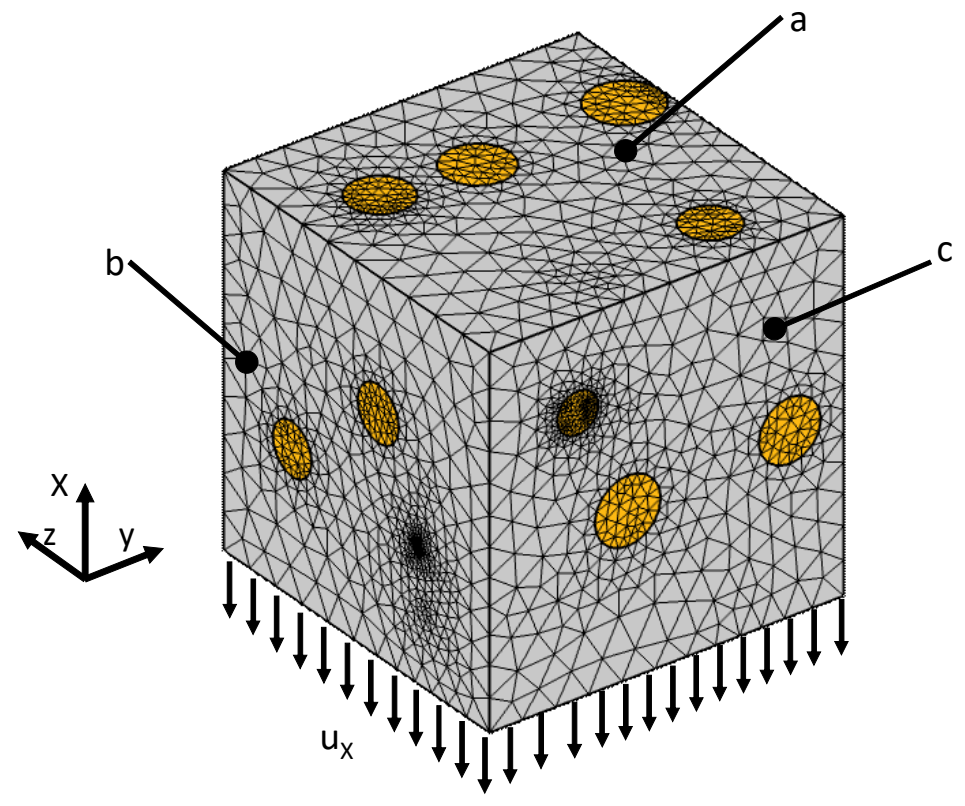

Fig. 3. Division into finite elements and applied boundary conditions

Aluminium 7091 was chosen for the matrix material. As a reinforcement $\mathrm{SiC}$ (Silicon Carbide). The mechanical-physical properties of the materials used are shown in Table 1.

Table 1

Mechanical-physical properties of materials used on the matrix and reinforcement [34-35]

\begin{tabular}{|c|c|c|c|}
\hline Material & $\begin{array}{c}\text { Young's } \\
\text { modulus, GPa }\end{array}$ & $\begin{array}{c}\text { Poisson's } \\
\text { ratio }\end{array}$ & $\begin{array}{c}\text { Density } \\
{\left[{\left.\mathbf{k g} \cdot \mathbf{m}^{-3}\right]}^{-3}\right.}\end{array}$ \\
\hline $\mathrm{Al} .7091$ & 74.9 & 0.37 & 2720 \\
\hline $\mathrm{SiC}$ & 458 & 0.17 & 3200 \\
\hline
\end{tabular}

To determine the effective properties of the composite material, formulas (2-4) were used:

- Young's modulus (2) (Hooke's law): 


$$
E=\frac{\sigma_{x}}{\varepsilon_{x}},
$$

- Poisson's ratio (3) (change in the material volume)

$$
v=-\frac{d V-\varepsilon_{x}}{2 \varepsilon_{x}}, d V=\varepsilon_{x}+\varepsilon_{y}+\varepsilon_{z},
$$

- density (4):

$$
\rho=-\frac{m}{a^{3}},
$$

where $\sigma_{x}$-averaged stress on the surface to which the $u_{x}$ displacement was applied;

$\varepsilon_{x}, \varepsilon_{y}, \varepsilon_{z}$ - strains respectively on $x, y$, and $z$-direction;

$m$ - total mass of the matrix and reinforcement.

\section{Results and discussion}

The parameters obtained from the FEM $\left(\sigma_{x}, \varepsilon_{x}, \varepsilon_{y}, \varepsilon_{z}, m\right)$ were implemented to the formulas (2-4), and then the effective properties of the particle - reinforced composite were determined. Because the location of the reinforcement particles was determined at random, for each composite configuration (particle size, volume fraction), five numerical simulations were performed. The average values of effective properties, together with the standard deviation (in round bracket), are shown in Table 2 . The effective mechanical-physical properties of the composites determined by the approximate solution [16] (without taking into account the random location of the reinforcement particles and their size) and the experiment [35] are also included in Table 2. The authors of [35] did not provide the size of the reinforcement particles, therefore, two different radii of the reinforcement particle (typical for the $\mathrm{SiC}$ material [34]) were assumed in the analyses performed.

Analysing the data presented in Table 2, one can notice a satisfactory correlation of the results obtained with those available in the literature.

\section{Effective mechanical-physical properties of the composite reinforced}

\begin{tabular}{|c|c|c|c|c|c|}
\hline \multirow{2}{*}{\multicolumn{2}{|c|}{ Property }} & \multicolumn{2}{|c|}{$V_{p}=10 \%$} & \multicolumn{2}{|c|}{$V_{p}=20 \%$} \\
\hline & & $r_{p}=0.05, \mathrm{~mm}$ & $r_{p}=0.1, \mathrm{~mm}$ & $r_{p}=0.05, \mathrm{~mm}$ & $r_{p}=0.1, \mathrm{~mm}$ \\
\hline \multirow{3}{*}{$E, \mathrm{Gpa}$} & FEM (this paper) & $87.47(0.27)$ & $83.69(0.57)$ & $102.98(0.18)$ & $100.39(1.1)$ \\
\hline & Experiment [35] & \multicolumn{2}{|c|}{87.6} & \multicolumn{2}{|c|}{105.5} \\
\hline & Approx. sol. [16] & \multicolumn{2}{|c|}{85.19} & \multicolumn{2}{|c|}{99.56} \\
\hline \multirow{2}{*}{$N$} & FEM (this paper) & $0.36(0)$ & $0.36(0)$ & $0.35(0)$ & $0.35(0)$ \\
\hline & Approx. sol. [16] & \multicolumn{2}{|c|}{0.36} & \multicolumn{2}{|c|}{0.35} \\
\hline \multirow{2}{*}{$\rho, \underset{3}{\mathrm{~kg}} \cdot \mathrm{m}^{-}$} & FEM (this paper) & $2766.2(0)$ & $2751.8(0.8)$ & $2814.38(0.13)$ & $2799.6(0.98)$ \\
\hline & Approx. sol. [16] & \multicolumn{2}{|c|}{2768} & \multicolumn{2}{|c|}{2816} \\
\hline
\end{tabular}

Table 2 with SiC particles (PRAMCs (SiC))

Also, when analysing the data presented in Table2, it can be seen that the effective Young's modulus depends on the size of the reinforcement particle - it increases as its radius decreases. Such regularity was also noted in [36]. This may be because with smaller dimensions of the reinforcement, the contact area of the reinforcement and the matrix increases, which makes the global deformation of the composite smaller.

As for the Poisson's ratio and density, the solutions obtained agree with the theoretical ones. Theoretically, the density of the composite should not depend on the radius of the SiC particles. However, it is noticeable that the relative density error increases as the radius of the reinforcement particles increases (Fig. 4b). This phenomenon is related to the way the composite is modelled. Namely, the number of particles calculated from formula (1) is rounded off to an integer. For larger particle radius, a larger rounding error occurs. 
a)

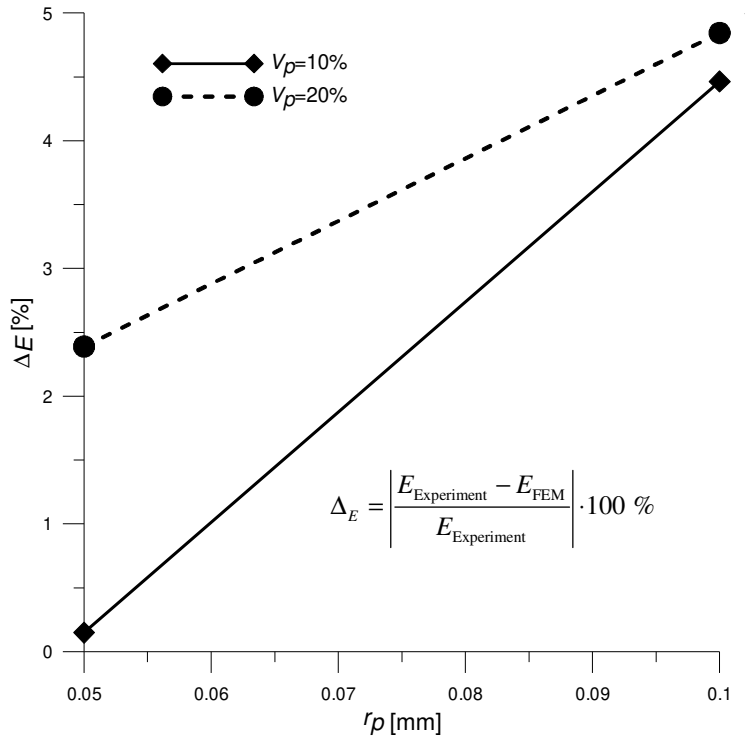

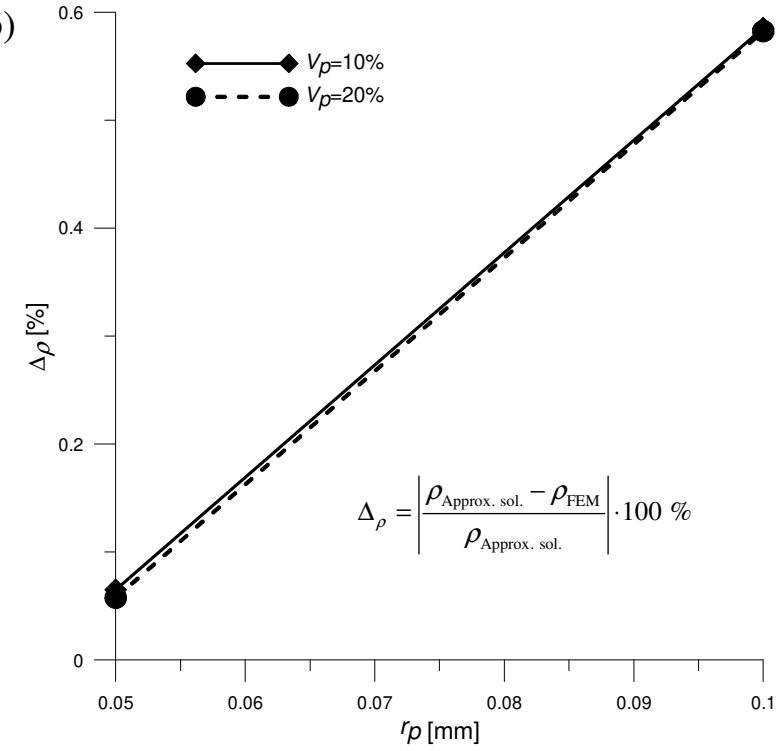

Fig. 4. Estimation of the accuracy of the results obtained: a - Young's modulus; b - density

\section{Conclusions}

1. The paper presents a method enabling determination of effective properties of particle reinforced metal matrix composites.

2. The developed method enables determination of Young's modulus, Poisson's ratio and density of PRAMCs composite, taking into account the impact of the random three-dimensional distribution of reinforcement particles, as well as their size and volume fraction.

3. Using the developed method, the effective properties of the PRAMCs composite reinforced with $\mathrm{SiC}$ particles were determined and the obtained results were compared with the literature data.

4. Satisfactory compliance of the obtained solutions with literature solutions was found:

- the maximum and minimum error in the estimation of Young's modulus was $4.84 \%$ $\left(V_{p}=20 \%, r_{p}=0.1 \mathrm{~mm}\right)$ and $0.15 \%\left(V_{p}=10 \%, r_{p}=0.05 \mathrm{~mm}\right)$, respectively;

- the maximum and minimum error of density estimation was $0.58 \%\left(V_{p}=20 \%, r_{p}=0.1 \mathrm{~mm}\right)$ and $0.06 \%\left(V_{p}=10 \%, r_{p}=0.05 \mathrm{~mm}\right)$, respectively;

- Poisson's ratios determined using the developed method were identical to the literature ones.

\section{Funding}

This publication was financed through the program of the Ministry of Science and Higher Education of Poland named "Regional Initiative of Excellence" in 2019-2022 project number 011/RID/2018/19.

\section{Acknowledgements}

This research was co-founded through the subsidy of the Ministry of Science and Higher Education for the discipline of Mechanical Engineering at the Faculty of Mechanical Engineering, Bialystok University of Technology.

\section{References}

[1] Edwards KL. Strategic substitution of new materials for old: applications in automotive product development. Materials and Design, vol. 25, 2004, pp. 529-533.

[2] Farag MM. Quantitative methods of materials substitution: application to automotive components. Materials and Design, vol. 29, 2008, pp. 374-80.

[3] Soutis C. Progress in Aerospace Sciences. Fibre reinforced composites in aircraft construction, vol. 41, 2005, pp. 143-151.

[4] Beck A.J., Hodzi A., Soutis C., Wilson C.W. Influence of Implementation of Composite Materials in Civil Aircraft Industry on reduction of Environmental Pollution and Greenhouse Effect. IOP Conference Series: Materials Science and Engineering, vol. 26, 2011, 012015, 10p. 
[5] Alves C., Ferrão P.M.C., Freitas M., Silva A.J., Luz S.M., Alves D.E. Sustainable design procedure: The role of composite materials to combine mechanical and environmental features for agricultural machines. Materials and Design, vol.30, 2009, pp. 4060-4068.

[6] Titov N.V., Kolomeichenko A.V., Logachev V.N., Kravchenko I.N., Litovchenko N.N. Investigation of the hardness and wear resistance of working sections of machines hardened by vibroarc surfacing using cermet materials. Welding International, vol. 29, 2015, pp. 737-739.

[7] Ondrachek G., The quantitative microstructure-field property correlation of multiphase and porous materials. Reviews on Powder Metallurgy and Physical Ceramics, vol.3(3-4), 1987, pp. 205-322.

[8] Skorokhod V. V., Layered composites: structural classification, thermophysical and mechanical properties. Powder Metallurgy and Metal Ceramics, vol. 42(9), 2003, pp. 437-446.

[9] Mieczkowski G. Description of stress fields and displacements at the tip of a rigid, flat inclusion located at interface using modified stress intensity factors. Mechanika, vol. 21(2), 2015, pp. 9198.

[10] Mieczkowski G. Stress fields at the tip of a sharp inclusion on the interface of a bimaterial. Mechanics of Composite Materials, vol. 52(5), 2016, pp. 601-610.

[11] Mieczkowski G., Molski K., Seweryn A. Finite-element modeling of stresses and displacements near the tips of pointed inclusions. Materials Science, vol. 43( 2), 2007, pp. 183-194.

[12] Rogowski G. Plastic zones for 3D planar cracks embedded in an elastic-plastic layer sandwiched between two elastic adherents. Theoretical and Applied Fracture Mechanics, vol. 98, 2018, pp. 199-209.

[13] Benveniste Y. A new approach to the application of Mori-Tanaka's theory in composite materials. Mechanics of Materials, vol. 6,1987, pp.6:147-57.

[14] Hashin Z, Shtrikman S. A variational approach to the theory of the elastic behaviour of multiphase materials. Journal of the Mechanics and Physics of Solids, vol. 11, 1963, pp. 127140.

[15] Walpole LJ. On bounds for the overall elastic moduli of inhomogeneous systems - I. Journal of the Mechanics and Physics of Solids, vol. 14, 1966, pp. 151-62.

[16] Murthy P. L. N., Goldberg R. K., Mital S. K. Micromechanics for particulate reinforced composites, NASA-TM-107276, NAS 1.15:107276, E-10344, 1996.

[17]Zienkiewicz O., Taylor Ro., Zhu J.Z. 2013, The Finite Element Method: Its Basis and Fundamentals. Oxford: Butterworth-Heinemann, 2013, 756p.

[18] Mieczkowski G., Borawski A., Szpica D. Static electromechanical characteristic of a three-layer circular piezoelectric transducer, Sensors, vol. 20, 2020, 222, 14p.

[19] Mieczkowski G. Electromechanical characteristics of piezoelectric converters with freely defined boundary conditions and geometry. Mechanika, vol. 22(4), 2016, pp. 265-272.

[20] Mieczkowski G. Static electromechanical characteristics of piezoelectric converters with various thickness and length of piezoelectric layers. Acta Mechanica et Automatica, vol.13(1), 2019, pp. 30-36.

[21] Szpica D. Investigating fuel dosage non-repeatability of low pressure gas-phase injectors. Flow Measurement and Instrumentation, vol. 59, 2018, pp. 147-156.

[22] Szpica D. Simplified numerical simulation as the base for throttle flow characteristics designation. Mechanika, vol. 21(2), pp. 129-133;

[23] Szpica D. Modeling of the operation of a Dual Mass Flywheel (DMF) for different engine-related distortions. Mathematical and Computer Modelling of Dynamical Systems, vol. 24(6), 2018, pp. 643-660.

[24] Borawski A. Suggested Research Method for Testing Selected Tribological Properties of Friction Components in Vehicle Braking Systems. Acta Mechanica et Automatica, vol. 10(3), 2016, pp. 223-226.

[25] Borawski A. Common methods in analysing the tribological properties of brake pads and discs - a review. Acta Mechanica et Automatica, vol. 13(3), 2019, pp. 189-199.

[26] Borawski A. Simulation Study of the Process of Friction in the Working Elements of a Car Braking System at Different Degrees of Wear. Acta Mechanica et Automatica, vol. 12(3), 2018, pp. 221-226.

[27] Eukaszewicz A. Temperature field in the contact zone in the course of rotary friction welding of metals, Materials Science, vol. 55 (1), 2019, pp. 39-45. 
[28]Łukaszewicz A., Panas K., Szczebiot R. Design process of technological line to vegetables packaging using CAx tools, Proceedings of 17th International Scientific Conference on Engineering for Rural Development, May 23-25, 2018, Jelgava, Latvia, pp. 871-876.

[29] Mieczkowski G. Criterion for crack initiation from notch located at the interface of bi-material structure Eksploatacja i Niezawodnosc - Maintenance and Reliability vol. 21 (2), 2019, pp. 301310.

[30] Shen Y.-L., Finot M., A. Needleman, Suresh S: Effective elastic response of two-phase composites. Acta Metallurgica et Materialia, vol. 42(1), 1994, pp. 77-97.

[31] Umer U., Ashfaq M., Qudeiri J. A., Hussein H. M. A., AL-Ahmari A. R. Finite element modeling of the orthogonal machining of particle reinforced aluminum based metal matrix. Modern Machinery Science Journal, vol. 4, 2014, pp. 511-515.

[32] Yan Y., Geng L., Li A., Fan G. Finite Element Analysis about Effects of Particle Size on Deformation Behavior of Particle Reinforced Metal Matrix Composites, Key Engineering Materials, Vol (353-358), 2007, pp 1263-1266.

[33]Ekici R, Apalak MK, Yıldırım M, Nair F. Effects of random particle dispersion and size on the indentation behavior of $\mathrm{SiC}$ particle reinforced metal matrix composites. Materials and Design, vol. 31, 2010, pp.2818-33.

[34] Girot F. A, Quenisset J.M., Naslain R. Discontinuously-reinforced aluminum matrix composites. Composites Science and Technology, vol. 30, 1987, pp. 155-184.

[35] Jeong H., Hsu D. K., Shannon R.E., Liaw P. K. Elastic Moduli of Silicon Carbide Particulate Reinforced Aluminum Metal Matrix Composites. Review of Progress in Quantitative Nondestructive Evaluation, vol. 9, 1990, pp. 1395-1402.

[36] Inegbenebor A.O.; Bolu C.A., Babalola P.O., Inegbenebor A.I., Fayomi O.S.I. Aluminum Silicon Carbide Particulate Metal Matrix Composite Development Via Stir Casting Processing. Silicon, vol. 10, 2018, pp. 343-347. 